\title{
The new consultant contract and women senior registrars
}

\author{
BERENICE BEAUMONT, ANNE GRÜNEBERG
}

If the profession regards the pricing as satisfactory the new consultant contract ${ }^{1}$ is likely to be implemented. The basis of the contract is a "standard" commitment of 10 notional halfdays (NHDs) a week. These would comprise eight clinical sessions, one session to take account of continuing commitment to patient care outside normal working hours, and one to cover administrative duties. Provision for posts of less than 10 NHDs is minimal in the new contract.

At present about $10 \%$ of consultants and $18^{\circ} \%$ of senior registrars are women. These percentages and the actual number of women doctors will continue to rise as the increased proportion of women among the medical student intake works its way through to senior hospital posts. Most of them will be married $^{2}$ and, at least during the early years of their consultant appointments, those with children will have a major responsibility for their children's care. The fact that this will increase the demand for limited-session work has been recognised in theory by the DHSS ${ }^{3}$ and the BMA. But no realistic provision to meet this demand has been made in the new contract.

The Medical Women's Federation has recently undertaken a study to discover the probable effect of the new contract on women senior registrars taking consultant appointments. The federation asked them how many clinical sessions they would wish to work. In May 1978 all regional medical officers in England and Wales and postgraduate hospitals were asked to send a short questionnaire to every woman senior registrar. We do not know how many of the approximately 400 women currently employed as senior registrars received questionnaires. (The difficulties of tracking down the senior registrar population are well known.) A total of 192 valid, completed questionnaires were received from all regions except Wessex. The purpose of the survey was to determine whether or not there were any women senior registrars whose requirements were not met by the new consultant contract.

\section{Survey findings}

The average age of respondents was 36 . Of these, $46^{\circ}{ }_{0}$ were between 30 and $34 ; 27 \%$ between 35 and 39; and almost all the rest were 40 or older. Of the respondents, $72 \%$ (139) were married and $57 \%$ (110) had at least one dependent child. Of those with children, $82 \%$ were at least 27 before their first child was born and $49 \%$ were 30 or older. Twenty-four respondents had relatives other than children dependent on them. Some $76 \%$ (146) considered themselves geographically tied, while $61 \%$ (117) were working full time. The specialties in which the respondents worked are set out in the table.

Respondents were asked how many clinical sessions they would prefer to work and would be able to work if applying for a consultant post now. Half (96) said eight or more clinical sessions; $29 \%$ (56) said that they would prefer less than eight

\footnotetext{
Kensington, Chelsea, and Westminster AHA (T)

BERENICE BEAUMONT, $\mathrm{MB}, \mathrm{MFCM}$, senior registrar in commurity medicine
}

Medical Women's Federation, London WC1H 9HX

ANNE GRUNEBERG, MB, FFARCS, honorary secretary
Specialties in which respondents to the survey worked

\begin{tabular}{|c|c|c|c|c|c|}
\hline \multicolumn{4}{|c|}{ Specialty } & \multirow[b]{2}{*}{$\begin{array}{r}\text { No } \\
45 \\
36 \\
36 \\
29 \\
15 \\
12 \\
5 \\
5 \\
9\end{array}$} & \multirow[b]{2}{*}{$\begin{array}{c}0_{0} \\
23 \\
18 \cdot 5 \\
18 \cdot 5 \\
15 \\
8 \\
6 \\
3 \\
3 \\
5\end{array}$} \\
\hline $\begin{array}{llr}\begin{array}{l}\text { Psychiatry } \\
\text { Pathology }\end{array} & \ldots & \ldots \\
\text { Medical } & \ldots & \ldots \\
\text { Anaesthetics } & \ldots & \ldots \\
\text { Radiology/radiotherapy } \\
\begin{array}{l}\text { Paediatrics } \\
\text { Obstetrics/gynaecology } \\
\text { Surgical }\end{array} & \ldots & \ldots \\
\text { Other/not } & \text { stated } & \ldots\end{array}$ & $\begin{array}{l}\cdots \\
\cdots \\
\cdots \\
\cdots \\
\cdots \\
\cdots \\
\cdots\end{array}$ & $\begin{array}{l}\cdots \\
\cdots \\
\cdots \\
\cdots \\
\cdots \\
\cdots \\
\cdots\end{array}$ & $\begin{array}{l}\cdots \\
\cdots \\
\cdots \\
\cdots \\
\cdots \\
\cdots \\
\cdots\end{array}$ & & \\
\hline All specialties & & & & 192 & 100 \\
\hline
\end{tabular}

clinical sessions but would accept a consultant post of eight or more if there were no alternative. The remaining 40 said that they would not take up a consultant appointment for which they were selected unless it were for less than eight clinical sessions. Of those respondents wanting less than eight sessions almost all preferred between five and seven. The doctors were not predominantly engaged in any one particular specialty. Almost all had a caring commitment for children or other relatives.

\section{Restrictive clause}

The new contract contains only one line which covers the particular position in which women are likely to find themselves: "All posts should be advertised in such a manner that candidates unable for personal reasons such as domestic responsibilities, disability, or ill-health to offer the minimum of 10 notional half-days (NHDs) are able to apply." This clause is appropriate except for its nonsensical restrictive conditions. In practice, it would mean that only candidates of exceptionally high ability or those applying for posts to which no other candidate was attracted would be appointed for limited sessions to posts advertised in these terms. All kinds of wrangles may be envisaged, such as whether or not the ownership of a cat constitutes a domestic commitment and to what extent one has to be crippled to qualify for this provision. The restrictions are not sensible and should be removed.

A draft implementation circular on the new consultant contract is being sent to all consultants and senior registrars. ${ }^{4}$ As a result of the MWF's representations on the need for posts with less than $10 \mathrm{NHDs}$, the circular contains some provision for new substantive limited session consultant posts in clause 12: "Where, exceptionally, an authority wishes to advertise a post for fewer than the standard 10 NHDs ... they may do so only with the approval of the DHSS." The proportion of women in the national medical school intake has already risen to $38 \%$. Is the need for this provision really going to be "exceptional ?" The necessity for special permission from the DHSS for limited-session contracts, not stated as being required for jobs of $10 \mathrm{NHDs}$ and more, is an invidious distinction which will lead to unnecessary delays and should be abolished.

The survey showed that at least $\mathbf{4 0}$ women senior registrars now training would be unable to take up a consultant appointment of eight clinical sessions. The respondents have shown a strong commitment to their careers by delaying having children until they have completed a substantial proportion of their 
postgraduate training. Several respondents commented that the present unavailability of limited session consultant posts made the schemes for part-time training, whatever their other inadequacies, pointless.

What will be the outcome of this minimal provision for limited session consultancies? The expensive training and hard-won skills of at least 40 doctors, and of their successors through the years, may be wasted. Half of the respondents to the survey said that they wanted to work less than 10 NHDs, so those working more would be working to a pattern out of tune with their assessment of their responsibilities in life. In the past there have been limited-session consultants as well as full-time ones in all hospital specialties. There is no reason why this should not be the case in the future.

\section{Necessary modifications}

The following modifications to the new contract are necessary:

(1) The restrictive conditions should be removed from the clause permitting candidates to apply who wish to work for fewer than 10 NHDs.

(2) All consultants now working less than full time should be able to transfer to a new limited session contract without restrictive conditions.

(3) A proportion of consultant posts in every specialty should be advertised for fewer than 10 NHDs. The proportion should be equal to at least half the proportion of women in senior registrar training. At least $9 \%$ of currently advertised consultant vacancies in all specialties should be for limited sessions. (At present $18 \%$ of senior registrars are women.)

If the new contract is not changed in this way the so-called equal opportunities for women will be seen as a cynical gesture and will lead to waste and heartbreak.

We are grateful to regional medical officers for distributing the survey questionnaire.

\section{References}

${ }^{1}$ British Medical fournal, 1978, 1, 1291.

${ }^{2}$ Beaumont, B, British Medical fournal, 1978, 1, 191.

3 Department of Health and Social Security, Women in Medicine. London, HMSO, 1975.

${ }^{4}$ British Medical fournal, 1978, 2, 1806.

\section{Council-continued}

The committee had accordingly recommended that the BMA should press for legislation to enable children born as the result of AID to which the husband of the mother had consented to be defined as legitimate from the moment that conception was confirmed. The recommendation was adopted.

Turning to the handling and use of medical data, $\mathrm{Dr}$ Thomas said that a national code of practice was required which would be enforceable by criminal sanctions to cover all persons handling medical information. It was necessary to ensure that all computerised medical handling conformed to the principles accepted by the DHSS (11 November 1978, p 1382). That would not be an excuse for a doctor to treat clinical information like confetti. It would strengthen the doctor's hand and if he believed that it was in the patients' clinical interests that he should share medical information with a non-medical person there was the assurance of further safeguards that the information would be kept confidential.

\section{Armed Forces Committee}

Colonel J C Watts presented the report of the Armed Forces Committee for the first time as its newly elected chairman. He referred to the report of the Armed Forces Review Body (23-30 December 1978, p 1806). The evidence from the BMA and the Ministry of Defence had pointed out the serious drop in numbers of armed Forces' doctors; these had fallen by 106 in the last three years; the number of cadets had fallen by 94 and the number of conversions from short service to long service commissions by 17. Also, there would soon be several retirements under the 16 -year rule. But the report's recommendations had taken no heed of the evidence and Colonel Watts said that he expected to have to come back to ask for the Council's help in correcting the serious position which had arisen in the medical section of the armed Forces.

\section{NHS industrial disputes: advice to doctors}

The BMA Council and the Joint Consultants Committee have recently discussed the effect of the current industrial action on patient care (p 357). Members emphasised that only doctors, who bear clinical responsibility for patients, could make decisions on the urgency of medical care. The BMA has received one report where an emergency meeting of consultants was necessary to prevent shop stewards, who were not medically qualified, from "checking up" on admissions. The AHA was left in no doubt that doctors alone could determine which patients were admitted.

Consultants' attention is drawn to the joint statement on disruption of hospital services issued by the Central Committee for Hospital Medical Services and the defence societies in October (28 October 1978, p 1244). Further advice was issued to consultants this week as follows:

(1) Consultants have an overriding duty to do all in their power to treat emergency and urgent cases by whatever means they can achieve. In addition, they have the commitment mentioned in the October statement to all inpatients already in their care.

(2) Other than this, their actions must be dictated by their decision, and their decision alone, as to what care if any can be extended to non-urgent cases, bearing in mind their local knowledge of the situation as it affects their hospital(s). Particular attention is drawn to the following extracts from the October statement:

"The decision that the patient requires emergency treatment is one which only a doctor is competent to make." "Consultants taking such action as they deem proper in the best interests of their patients may rely on the full support of the BMA and the defence societies."

The Secretary of the BMA comments: Where a dispute limits the services available to patients, the medical profession locally should resist any attempt by others to usurp its authority and insist that only doctors are qualified to decide priorities. If other staff prevent their determining these priorities .. doctors should advise each patient of the situation, record the fact that this has been done in the patient's notes, and inform the appropriate health authority, including the family practitioner committee where appropriate, in writing."

\section{Shortage of drugs}

An agreement has been made between the DHSS, the General Medical Services Committee, and the Pharmaceutical Services Negotiating Committee for arrangements to deal with shortages of drugs because of current industrial action. The arrangements will apply to prescriptions dispensed on or after 1 February and will be subject to regular review. Where supplies run short pharmacists will be permitted to dispense a generically equivalent drug for the one prescribed if stocks of the latter have run out. In these circumstances the prescription will be endorsed "PNC-E" (prescriber not contacted-emergency). Should the situation deteriorate to the extent that neither the drug prescribed nor a generic equivalent is available it has been agreed that the pharmacist will in all circumstances contact the prescriber before making any change. If he is unable to contact the prescriber the patient will have to be referred back.

\section{DHSS advice}

The DHSS has recommended that doctors who find that they are unable to provide adequate medical care because of industrial action should contact the regional health authority immediately. If difficulties continue doctors should contact the BMA. 